\title{
Angiotensin Converting Enzyme Inhibitor Fetopathy
}

National Cancer Institute

\section{Source}

National Cancer Institute. Angiotensin Converting Enzyme Inhibitor Fetopathy. NCI Thesaurus. Code C111908.

Fetal embryopathy associated with maternal angiotensis converting enzyme (ACE) inhibitor use during pregnancy that may include fetal acute renal failure, growth restriction, oligohydramnios, calvaria abnormalities, preterm birth, and pulmonary hypoplasia with respiratory distress. 